\title{
Deletion of Ecto-5' -Nucleotidase (CD73) Reveals Direct Action Potential-Dependent Adenosine Release
}

\author{
Boris P. Klyuch, Nicholas Dale, and Mark J. Wall \\ School of Life Sciences, University of Warwick, Coventry CV4 7AL, United Kingdom
}

Purinergic signaling is a highly complex system of extracellular communication involved in many physiological and pathological functions in the mammalian brain. Its complexity stems from the multitude of purine receptor subtypes and endogenous purine receptor ligands (including ATP, ADP, UTP, UDP, and adenosine). Potentially all of these ligands could be directly released, and some could also arise from extracellular metabolism. A widely held consensus is that, except under pathological conditions, extracellular adenosine arises only from ectoATPase-mediated metabolism of previously released ATP. Here, we have used mice that lack the CD73 gene (encoding ecto-5'-nucleotidase that converts AMP to adenosine) to test whether action potential-dependent adenosine release in the cerebellum depends on prior ATP release. Surprisingly, we have uncovered two parallel pathways of adenosine release: one that is indirect via glutamate receptor-dependent release of ATP and a second of equal amplitude that has no dependence on prior release of ATP and thus represents the direct release of adenosine. This component of adenosine release is blocked by bafilomycin and modulated by mGlu4 receptor activation, strongly supporting adenosine release by exocytosis from parallel fibers. Our findings are a major step in understanding the mechanisms of adenosine release and are likely to have implications for all aspects of physiology where adenosine plays a key modulatory role.

\section{Introduction}

The purine adenosine is an important neuromodulator involved in many physiological and pathological processes in the mammalian CNS (Abbracchio et al., 2009). Although the signaling actions of adenosine are well characterized, via the activation of G-protein-coupled receptors, the precise mechanisms of how adenosine is released into the extracellular space remain unclear (Abbracchio et al., 2009). Current evidence suggests that in pathological conditions (such as ischemia) adenosine is directly released (Dale and Frenguelli, 2009), whereas in physiological processes adenosine arises from prior released ATP and its subsequent extracellular metabolism (Halassa and Haydon, 2010).

We have described previously how stimulation in the molecular layer of the cerebellum increases extracellular adenosine concentration, a process that is both $\mathrm{Ca}^{2+}$ - and action potentialdependent and is resistant to equilibrative nucleotide transporter (ENT) inhibition. The released adenosine inhibits parallel fiber glutamate release and produces feedback inhibition of its own release (Wall and Dale, 2007). Although there is no evidence that the adenosine arises from prior ATP release, the lack of potent ecto-ATPase or 5'nucleotidase inhibitors (Wall et al., 2008) has

Received Dec. 6, 2011; revised Jan. 24, 2012; accepted Jan. 28, 2012.

Author contributions: B.P.K., N.D., and M.J.W. designed research; B.P.K. and M.J.W. performed research; B.P.K. and M.J.W. analyzed data; B.P.K., N.D., and M.J.W. wrote the paper.

This work was supported by the Medical Research Council of the United Kingdom. CD73 mice were kindly supplied by Prof. Jürgen Schrader, Heinrich Heine University, Düsseldorf, Germany. We thank Dr. Helen Brown, Samantha Dixon, and staff at the Genomics Facility at the University of Warwick for genotyping the mice and Prof. Bruno Frenguelli for commenting on earlier drafts of the manuscript.

This article is freely available online through the J Neurosci Open Choice option.

Correspondence should be addressed to Mark J. Wall at the above address. E-mail: mark.wall@warwick.ac.uk.

DOI:10.1523/JNEUROSCI.6052-11.2012

Copyright $\odot 2012$ the authors $\quad 0270-6474 / 12 / 323842-06 \$ 15.00 / 0$ prevented the resolution of the mechanism of adenosine release (Wall and Dale, 2007). Here, we have used mice that lack ecto5 '-nucleotidase (CD73), a key enzyme required for the conversion of ATP to adenosine, to determine the mechanism of adenosine release and whether it arises from prior release of ATP.

\section{Materials and Methods}

Experimental design. The $c d 73$ gene was disrupted in C57BL/6 mice by homologous recombination and activation of the Cre-loxP system (Koszalka et al., 2004). Mice were generated by the interbreeding of heterozygous CD73 mice. Comparison of adenosine release and synaptic transmission in $C D 73^{+/+}$and $C D 73^{-1-}$ mice was performed with an interleaved design using slices from $C D 73^{+/+}$and $C D 73^{-/-}$mice (littermates).

Cerebellar slice preparation. Transverse slices of cerebellar vermis $(400$ $\mu \mathrm{m})$ were prepared from 8 - to 10 -week-old $C D 73^{+/+}$and $C D 73^{-1-}$ mice of either sex and 3- to 4-week-old male Wistar rats. Mice and rats were killed by cervical dislocation and decapitated, in accordance with the UK Animals (Scientific Procedures) Act of 1986. The cerebellum was removed, and slices were cut on a Microm HM 650V microslicer in $\left(2-4^{\circ} \mathrm{C}\right.$ ) high $\mathrm{Mg}^{2+}$ and low $\mathrm{Ca}^{2+}$ ACSF, composed of (in mM): 127 $\mathrm{NaCl}, 1.9 \mathrm{KCl}, 8 \mathrm{MgCl}_{2}, 0.5 \mathrm{CaCl}_{2}, 1.2 \mathrm{KH}_{2} \mathrm{PO}_{4}, 26 \mathrm{NaHCO}_{3}$, and 10 D-glucose ( $\mathrm{pH} 7.4$ when bubbled with $95 \% \mathrm{O}_{2}$ and $5 \% \mathrm{CO}_{2}$ ). Slices were stored in ACSF $\left(1.3 \mathrm{mM} \mathrm{MgCl}_{2}\right.$ and $\left.2.4 \mathrm{mM} \mathrm{CaCl}_{2}\right)$ at $32^{\circ} \mathrm{C}$ for at least $1 \mathrm{~h}$ before recording.

Biosensor recording. Purine biosensors were obtained from Sarissa Biomedical Ltd. Two types of sensor were used: null sensors to control for electro-active interferents and adenosine biosensors responsive to adenosine (and metabolites). Before and after experiments, biosensors were calibrated with $10 \mu \mathrm{m}$ adenosine. A detailed description of adenosine biosensor properties has been published previously (Llaudet et al., 2003).

An individual slice was transferred to a recording chamber and perfused at $6 \mathrm{ml} / \mathrm{min}\left(32^{\circ} \mathrm{C}\right)$. To evoke adenosine release, trains $(50-200$ stimuli; $20 \mathrm{~Hz} ; 5$ min interval between trains) and square voltage pulses 
A

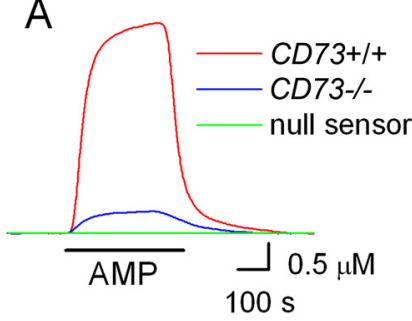

C $C D 73^{-1-}$

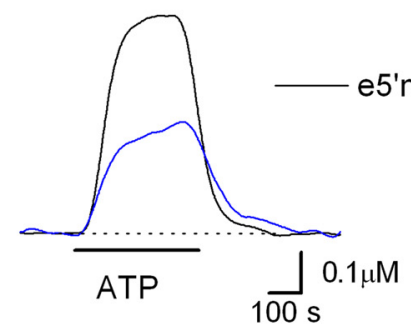

$\mathrm{F} C D 73^{+/+}$

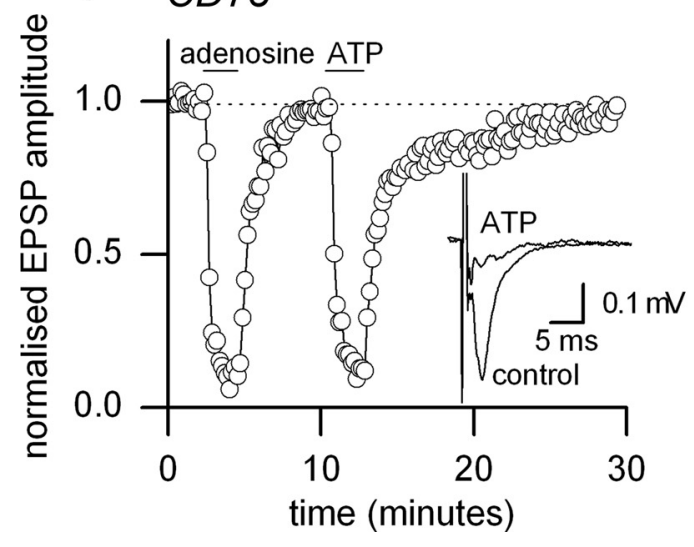

B

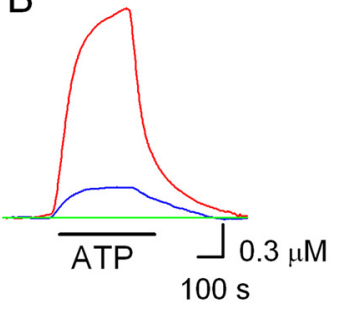

D $C D 73^{+/+}$

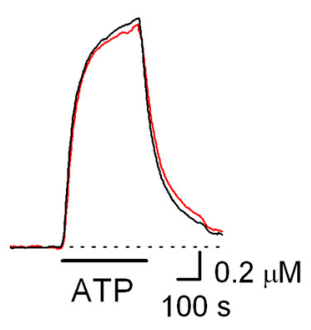

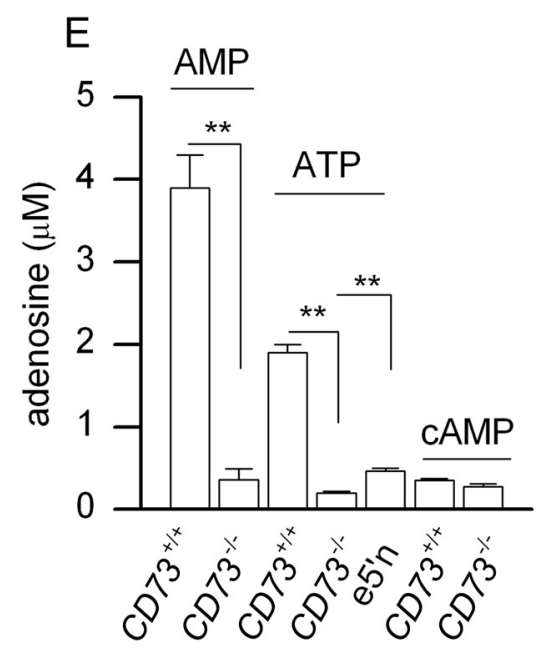

\section{G $C D 73^{-1-}$}

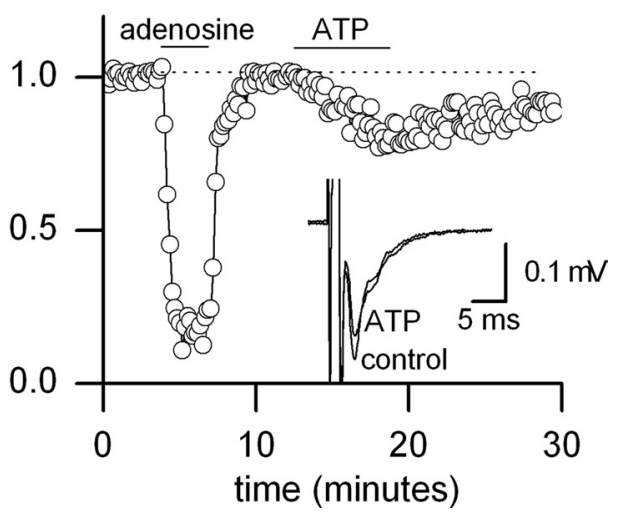

Figure 1. The lack of $C D 73$ prevents the metabolism of AMP and ATP to adenosine. $A$, Superimposed adenosine biosensor and null traces illustrating production of adenosine from $30 \mu m$ AMP by cerebellar slices from $C D 73^{+/+}$and $C D 73^{-1-}$ mice. $B$, As in $A$ but for $30 \mu \mathrm{m}$ ATP. C, Addition of $5^{\prime}$ nucleotidase (e5' $\mathrm{n} ; 5 \mathrm{kU} / \mathrm{ml}$ ) increased adenosine production from ATP (30 $\mu \mathrm{m}$ ) in a slice from a $C D 73^{-1-}$ mouse. $\boldsymbol{D}$, Application of $5^{\prime}$ nucleotidase $(5 \mathrm{kU} / \mathrm{ml})$ had little effect on adenosine production in a slice from a $C D 73^{+/+}$mouse. E, Graph summarizing conversion of AMP, ATP, and cAMP into adenosine by slices from $C D 73^{+/+}$and $C D 73^{-/-}$mice (e5' $\mathrm{n}$ : breakdown of ATP into adenosine by slices from $C D 73^{-1-}$ mice in the presence of $5 \mathrm{kU} / \mathrm{ml}$ of $5^{\prime}-$ nucleotidase; $\left.n=4-5\right)$. ${ }^{* *} p<$ 0.01 , Student's $t$ test. $F$, Graph plotting the amplitude of individual normalized parallel fiber fEPSPs against time recorded from a cerebellar slice from a $C D 73^{+/+}$mouse. Inset, superimposed fEPSP averages in control and $100 \mu \mathrm{M}$ ATP. G, As in $\boldsymbol{F}$ but for a slice from a $C D 73^{-1-}$ mouse. Inset, superimposed fEPSP averages in control and $100 \mu \mathrm{M}$ ATP.

(200 $\mu$ s duration) were delivered by a stimulator ISO-STIM (NPI) via a bipolar stimulating electrode (FHC) on the surface of the molecular layer, with adenosine detected by a biosensor (Klyuch et al., 2011). The substances used to modulate adenosine release had no effect on biosensor sensitivity. For the bafilomycin experiments, bafilomycin (or in control, $0.1 \%$ DMSO) was applied for up to $90 \mathrm{~min}$. To determine whether the effects of bafilomycin were significant, normalized data (calculated relative to the mean amplitude in control) were compared with an unpaired $t$ test for pooled data collected between 40 and $60 \mathrm{~min}$. Biosensor signals were acquired at $1 \mathrm{kHz}$ with a Micro 1401 interface using Spike 2 (V 6.1) software (Cambridge Electronics Design).

Parallel fiber fEPSPs. For parallel fiber stimulation, square voltage pulses (200 $\mu$ s duration) were delivered by a stimulator (model 2100, AM Systems) via a bipolar stimulating electrode (FHC) on the surface of the molecular layer. The recording electrode (an ACSF-filled microelectrode) was placed on the same track along which the parallel fibers travel. Confirmation of parallel fiber fEPSP identity was achieved by observation of paired-pulse facilitation and inhibition with glutamate receptor antagonists. Extracellular recordings were made by using an ISO-DAM amplifier (WPI), filtered at $1 \mathrm{kHz}$, and digitized on line $(10 \mathrm{kHz})$ with a Micro 1401 interface controlled by Spike 2 (V 6.1) software.
Drugs. All drugs were made up as stock solutions (1-100 mM), stored frozen, and then thawed and diluted with ACSF on the day of use. Adenosine, AMP, cAMP, and erythro-9-(2-hydroxy-3-nonyl) adenine (EHNA) were purchased from Sigma. ATP was purchased from Roche. Bafilomycin A1 (dissolved in DMSO before adding to ACSF), L-(+)-2amino-4-phosphonobutyric acid (L-AP4), TTX, and CNQX were purchased from Ascent Scientific. Soluble 5'-nucleotidase (Enzo Life Science) was dialyzed by using a dialysis system (Thermo Scientific; MW cutoff 10,000) to remove enzyme stabilizers.

Statistics. The data are presented as mean \pm SEM. Statistical significance was assessed by using paired and unpaired Student's $t$ tests with $p<$ 0.05 as significant.

\section{Results}

Metabolism of AMP and ATP to adenosine is greatly reduced in cerebellar slices from $C D 73^{-1-}$ mice

To determine whether spike-dependent adenosine release requires the release of ATP and its subsequent metabolism, we used mice with deletion of the gene coding for the enzyme CD73 (converts extracellular AMP to adenosine) (Koszalka et al., 2004). To quantify how the conversion of ATP, AMP, and cAMP to aden- 
osine is reduced in these mice, we applied exogenous AMP, ATP, and cAMP to cerebellar slices from $C D 73^{-1-}$ and $C D 73^{+/+}$mice and used biosensors (Llaudet et al., 2003) to measure their conversion to adenosine by native enzymes in the slice. After application of AMP $(30 \mu \mathrm{M})$ to $C D 73^{+/+}$slices, $3.9 \pm 0.4 \mu \mathrm{M}$ adenosine $(n=5)$ was detected (Fig. $1 A, E)$. In $C D 73^{-1-}$ slices, the production of adenosine from AMP was greatly reduced $(0.4 \pm 0.1 \mu \mathrm{M}$ adenosine; $n=5 ; p<0.01$ ) (Fig. $1 A, E)$. This represents a reduction in AMP metabolism of $\sim 91 \%$; thus, $<10 \%$ of AMP is metabolized independently of CD73. A similar reduction $(\sim 89 \%)$ in adenosine production was observed after application of $30 \mu \mathrm{M}$ ATP $\left(C D 73^{+/+}, 1.8 \pm 0.2 \mu \mathrm{M}, n=6\right.$; $C D 73^{-l-}, 0.2 \pm 0.05 \mu \mathrm{M}, n=5 ; p<0.01$ ) (Fig. $1 B, E$ ). Therefore, in slices from $C D 73^{-1-}$ mice additional enzymatic pathways are not upregulated to bypass the lack of CD73 and allow ATP metabolism to adenosine, confirming previous studies (Langer et al., 2008). The small amount of adenosine produced from ATP and AMP may be the action of alkaline phosphatase or the ectonucleotide pyrophosphatase/phosphodiesterase family of enzymes (Zimmermann, 2000), which appear unchanged in expression and activity by deletion of CD73 (Langer et al., 2008). Only a minor proportion of applied cAMP $(30 \mu \mathrm{M})$ was converted to adenosine by slices from either $C D 73^{+/+}$mice $(347 \pm 25 \mathrm{nM} ; n=$ 4) or $C D 73^{-1-}$ mice $(275 \pm 31 \mathrm{nM} ; n=4)$ (Fig. $\left.1 E\right)$, suggesting cAMP breakdown is limited by conversion of cAMP to AMP (by phosphodiesterase) (Gereau and Conn, 1994).

\section{The metabolism of ATP to adenosine can be rescued with} exogenous soluble $5^{\prime}$-nucleotidase

Because $C D 73^{-1-}$ mice can still metabolize ATP to AMP (deletion of the CD73 gene has no effect on brain ectoATPase activity or expression) (Langer et al., 2008), we attempted to rescue the production of adenosine from ATP by the addition of exogenous 5 '-nucleotidase. Application of soluble 5 '-nucleotidase enzyme $(5 \mathrm{kU} / \mathrm{ml})$ almost doubled $(96 \pm 5 \%$ increase; $n=5)$ the breakdown of ATP to adenosine in slices from $C D 73^{-1-}$ mice (increased from $237 \pm 14$ to $464 \pm 32 \mathrm{~nm} ; p<0.01$ ) (Fig. $1 C, E$ ), with little effect on adenosine release in slices from $C D 73^{+/+}$mice $(11 \pm 1 \%$ increase; $n=6$ ) (Fig. $1 D)$. In an additional three slices, we increased the concentration of soluble $5^{\prime}$-nucleotidase (from 5 to $15 \mathrm{kU} / \mathrm{ml}$ ) and found a significant increase in the conversion of ATP to adenosine $(5 \mathrm{kU} / \mathrm{ml}, 78 \pm 16 \% ; 15 \mathrm{kU} / \mathrm{ml}, 209 \pm 40 \%)$. Thus the degree of rescue was limited by the concentration of applied enzyme.

\section{The inhibition of synaptic transmission by ATP is reduced in $\mathrm{CD}^{-1-}$ mice}

We next verified the integrity of synaptic transmission in cerebellar slices from $C D 73^{-I-}$ mice compared with slices from $\mathrm{CD} 3^{+/+}$mice by recording parallel fiber-Purkinje cell fEPSPs. fEPSPs recorded in slices from $C D 73^{+/+}$and $C D 73^{-1-}$ mice had similar amplitudes $(0.28 \pm 0.03$ vs $0.24 \pm 0.05 \mathrm{mV}$, with equivalent stimulation strengths; $n=9$ for each genotype), showed the same degree of paired-pulse facilitation ( $50 \mathrm{~ms}$ interpulse interval, $1.3 \pm 0.03$ vs $1.4 \pm 0.07)$, and were equally reduced in amplitude by $100 \mu \mathrm{M}$ adenosine ( $87 \pm 4$ vs $83 \pm 6 \%$ inhibition) (Fig. $1 F, G)$. Application of ATP $(100 \mu \mathrm{M})$ produced almost the same reduction in fEPSP amplitude as adenosine $(100 \mu \mathrm{M})$ in slices from $C D 73^{+/+}$mice $(79 \pm 5$ vs $87 \pm 4 \%$ ) (Fig. $1 F$ ), with the effects of both adenosine and ATP abolished by the $\mathrm{A}_{1}$ receptor antagonist 8 -cyclopentyltheophylline ( $8 \mathrm{CPT})(2 \mu \mathrm{M} ; n=5)$ (data not shown). In contrast, the inhibitory effects of ATP on fEPSPs were significantly $(p<0.01)$ reduced compared with those of
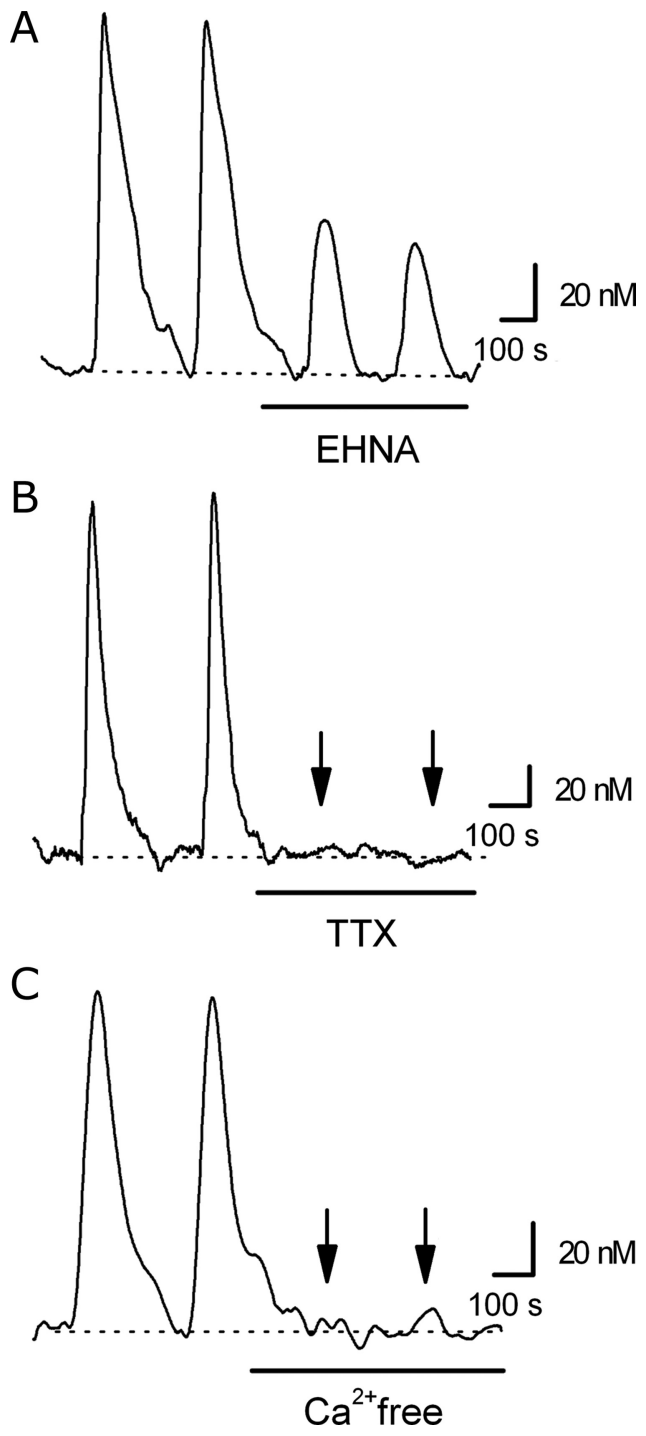

Figure 2. Properties of adenosine release in CD73 mice. $A$, Adenosine biosensor trace showing adenosine release evoked twice in control and then reduced after EHNA (20 $\mu \mathrm{m})$ application. $\boldsymbol{B}$, TTX (1 $\mu \mathrm{M})$ abolished adenosine release (arrows show where stimulations occurred but no adenosine was detected). $\boldsymbol{C}$, Adenosine release was abolished in ACSF containing no $\mathrm{Ca}^{2+}$ and 1 mm EDTA. The biosensor traces in $\boldsymbol{A}$ and $\boldsymbol{B}$ were recorded from slices from $C D 73^{+/+}$mice, whereas in $C$ the slice was from a $C D 73^{-1-}$ mouse.

adenosine in slices from $C D 73^{-1-}$ mice $(19 \pm 4$ vs $83 \pm 6 \%$ inhibition) (Fig. 1G). This provides independent evidence that the deletion of the $5^{\prime}$-nucleotidase in $C D 73^{-1-}$ mice greatly reduces the conversion of ATP to adenosine and thus alters the ability of exogenous ATP to inhibit synaptic transmission.

\section{Adenosine release can be evoked in cerebellar slices from $\mathrm{CD}^{+/+}$and $\mathrm{CD}^{+1-}$ mice}

To investigate whether spike-dependent adenosine release (Wall and Dale, 2007; Klyuch et al., 2011) can be evoked in cerebellar slices from $C D 73^{+1+}$ and $C D 73^{-1-}$ mice, we stimulated in the molecular layer and measured resultant adenosine release with adenosine biosensors (Llaudet et al., 2003). Adenosine biosensor currents could be measured (after stimulation) in slices from both $C D 73^{+1+}$ and $C D 73^{-1-}$ mice. Because adenosine biosensors can detect inosine and hypoxanthine as well as adenosine, we used the adenosine deaminase inhibitor (EHNA) to determine whether adenosine was released (Wall and Dale, 2007; Klyuch et 
A

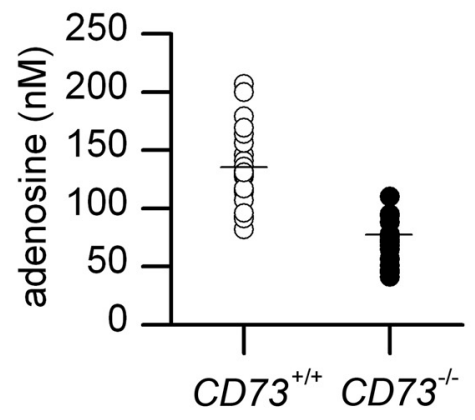

C $C D 73^{-1-}$

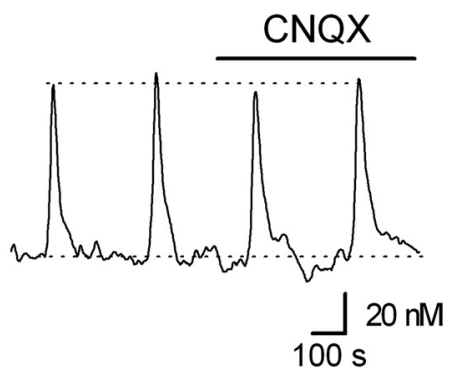

E $C D 73^{-1-}$

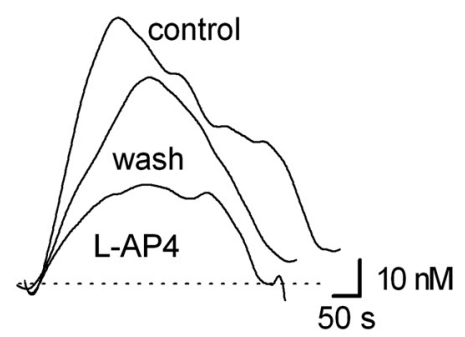

Figure 3. L Loss of $C D 73$ expression reveals direct adenosine release. $A$, Graph summarizing adenosine release measured from 21 and 18 slices from $C D 73^{-1-}$ and $C D 73^{+/+}$mice, respectively. Each point represents the concentration of adenosine evoked by stimulation from an individual slice. The lines represent the mean concentrations of adenosine detected in slices from $C D 73^{+/+}$ and $C D 73^{-1-}$ mice. $B$, Adenosine release evoked in a slice from a $C D 73^{+1+}$ mouse is reduced by $\sim 50 \%$ after the block of ionotropic glutamate receptors with $20 \mu \mathrm{M}$ CNQX.C, CNQX (20 $\mu \mathrm{m}$ ) has no effect on the adenosine release evoked in a slice from a $C D 73^{-1-}$ mouse. $\boldsymbol{D}$, Graph summarizing the adenosine release data $(n=5-6) .{ }^{* *} p<0.01$, Student's test. $\boldsymbol{E}$, Evoked adenosine release in a slice from a $C D 73^{-1-}$ mouse was reversibly reduced by the mGlu4 receptor agonist L-AP4 (50 $\left.\mu \mathrm{m}\right)$.

was $\sim 50 \%$ smaller than that detected in slices from $C D 73^{+/+}$mice (respectively, $69 \pm 5 \mathrm{nM}, n=18$ and $135 \pm 7 \mathrm{nM}, n=21$; $p<0.01$ ) (Fig. 3A). This reduction in adenosine did not arise from an increased tone of extracellular adenosine and consequent inhibition of adenosine release (Wall and Dale, 2007), because the effects of the $\mathrm{A}_{1}$ receptor antagonist $8 \mathrm{CPT}(2 \mu \mathrm{M})$ were not significantly different on adenosine release in slices from $C D 73^{+/+}$and $C D 73^{-1-}$ mice (mean increase, respectively, $13 \pm 6 \%, n=5$ and $7 \pm 5 \%, n=7$; $p=0.42$ ). This result suggests that at least some of the spike-evoked adenosine release originates from prior release of ATP.

\section{$C D 73^{-/-}$mice lack the glutamate receptor-dependent component of cerebellar adenosine release}

We next examined the components of spike-evoked adenosine release more closely. Unlike in slices from rats (Wall and Dale, 2007), we found a component of spike-evoked adenosine release in cerebellar slices from $C D 73^{+/+}$mice that depended on ionotropic glutamate receptor activation. This component was blocked by $20 \mu \mathrm{M}$ CNQX, which reduced adenosine release from $135 \pm 7$ to $69 \pm 10 \mathrm{nM}$ $(n=6 ; p<0.01)$ (Fig. $3 B, D)$. By contrast, in slices from $C D 73^{-1-}$ mice, we found that adenosine release was entirely independent of the activation of ionotropic glutamate receptors ( $76 \pm 8 \mathrm{nM}$ in control vs $71 \pm 12 \mathrm{nM}$ in $20 \mu \mathrm{M}$ CNQX; $n=5$ ) (Fig. $3 C, D$ ). A comparison of adenosine release in the presence of CNQX showed that glutamate receptor-independent adenosine release was identical in slices from $C D 73^{+/+}$and $C D 73^{-1-}$ mice $(p=$ $0.88)$. Thus in slices from mice that were unable to break down ATP to adenosine, there was no glutamate receptordependent component of adenosine release, which must therefore require prior ATP release. In contrast, the component al., 2011). EHNA $(20 \mu \mathrm{M})$ produced a $65 \pm 6 \%$ reduction in biosensor currents $\left(n=3, C D 73^{+/+} ; n=2, C D 73^{-/-}\right)$(Fig. $\left.2 A\right)$ and thus, like in cerebellar slices from rats (Wall and Dale, 2007; Klyuch et al., 2011), the major purine released by stimulation was adenosine. Adenosine release was action potential-dependent (blocked by $1 \mu \mathrm{M}$ TTX; $n=2, C D 73^{+/+} ; n=2, C D 73^{-I-}$ ) (Fig. $2 B$ ) and abolished by the removal of extracellular $\mathrm{Ca}^{2+}$ (with 1 mM EGTA; $n=3, C D 73^{+/+} ; n=2, C D 73^{-1-}$ ) (Fig. $2 C$ ). Therefore action potential (spike) and $\mathrm{Ca}^{2+}$-dependent adenosine release can be evoked in cerebellar slices from both $C D 73^{+/+}$and $\mathrm{CD}^{-1-}$ mice.

\section{Adenosine release is reduced in cerebellar slices from $\mathrm{CD}^{-1-}$ mice}

Although spike-dependent adenosine release could be evoked in slices from $\mathrm{CD} 73^{-1-}$ mice, the amount of adenosine measured of adenosine release that was independent of glutamate receptors must represent the direct release of adenosine because it remained unchanged in slices from $C D 73^{-1-}$ mice. Adenosine release in slices from $C D 73^{-1-}$ mice was significantly $(p<0.01)$ and reversibly inhibited by the mGlu4 receptor agonist L-AP4 (50 $\mu \mathrm{M} ; 45.8 \pm 10 \%$ reduction; $n=4$ ) (Fig. $3 E$ ), which is consistent with the hypothesis (Wall and Dale, 2007) that adenosine is directly released from parallel fibers (the only cerebellar component that expresses mGlu4 receptors) (Mateos et al., 1998).

\section{Exocytosis of adenosine}

To investigate the mechanism of direct adenosine release in more detail we used bafilomycin A1 (a vesicular $\mathrm{H}^{+}$-ATPase inhibitor). Bafilomycin prevents the refilling of synaptic vesicles and leads to a loss of vesicular neurotransmitter release (Zhou et al., 2000). If direct adenosine release occurs by exocytosis it should 
A

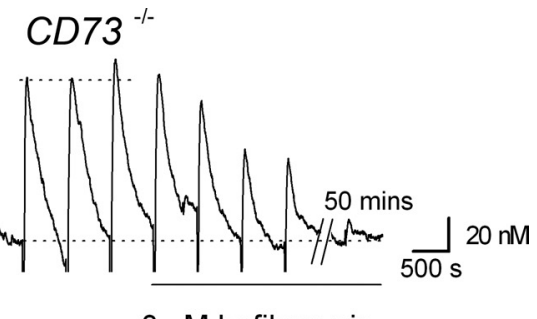

$3 \mu \mathrm{M}$ bafilomycin

\section{B $\quad C D 73^{-1-}$}
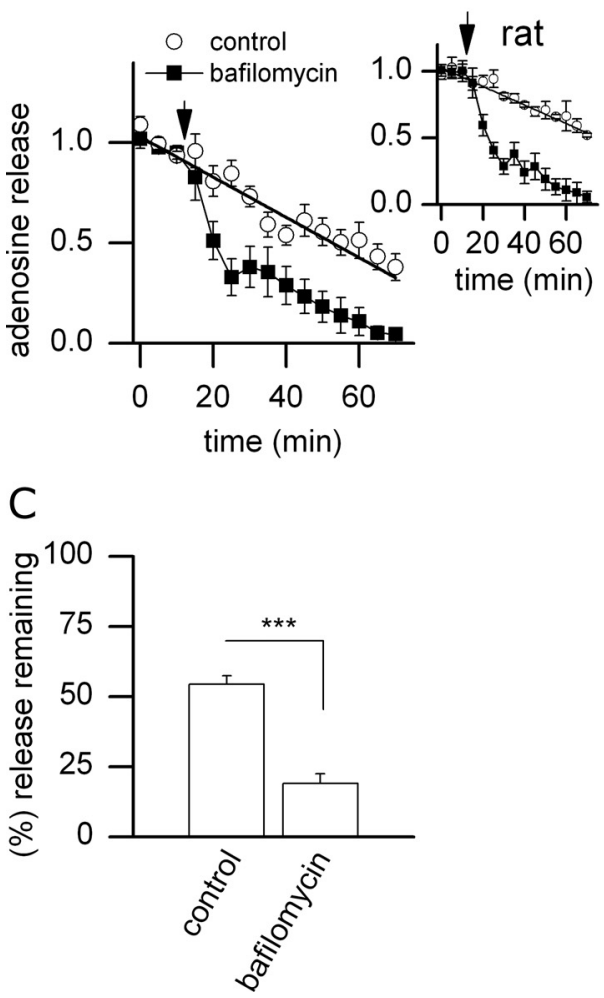

Figure 4. Direct adenosine release is blocked by bafilomycin. $A$, Adenosine release evoked in a slice from a $\mathrm{CD}_{3} 3^{-1-}$ mouse was reduced and almost abolished after incubation with bafilomycin $(3 \mu \mathrm{M})$. $\boldsymbol{B}$, Graph summarizing the effect of bafilomycin incubation on adenosine release evoked in slices from $C D 73^{-1-}$ mice $(n=7)$ compared with interleaved control slices $(n=6)$. Where bafilomycin $(3 \mu \mathrm{M})$ or DMSO $(0.1 \%)$ was applied is indicated by the arrow. The adenosine release has been normalized by dividing by the mean concentration of adenosine released by the control stimulations. The rundown of adenosine release in control was described by a linear fit $\left(R, 0.93\right.$; slope, $\left.0.01 \mathrm{~min}^{-1}\right)$. Inset, same as $\boldsymbol{B}$ but in slices from rats. $\boldsymbol{C}$, Graph plotting the mean percentage of adenosine release remaining after $40-60 \mathrm{~min}$ in control and bafilomycin. ${ }^{* * *} p<0.001$, Student's $t$ test.

therefore be greatly reduced or abolished by bafilomycin. Adenosine release was evoked (with a 5 min interval between stimulations) in slices from $C D 73^{-1-}$ mice and, whether the adenosine release remained reasonably stable for at least three stimulations, then either bafilomycin A1 (3 $\mu \mathrm{M})$ (Fig. $4 A$ ) or, in interleaved control experiments, the bafilomycin solvent (DMSO) was applied $(0.1 \%)$. Adenosine release showed rundown in control conditions, which could be described by a linear fit (slope $1 \% \mathrm{~min}^{-1}$; $n=6$ ) (Fig. $4 B$ ). This may reflect depletion of the intracellular releasable pool of adenosine, possibly as a result of a slow pool restock rate (Klyuch et al., 2011). Application of bafilomycin caused a fall in adenosine release that was faster than the rate of rundown (Fig. 4B). After 40-60 min, there was significantly less adenosine released in bafilomycin compared with control (per- centage adenosine remaining: $19 \pm 3.5$ vs $54.4 \pm 3 \%$; $p>0.001$; $n=7$ ) (Fig. 4C) with bafilomycin causing the complete block of adenosine release in most slices (Fig. $4 B$ ). Similar effects were observed in rat slices (Fig. $4 B$, inset; $n=4$ ), where there is only glutamate receptor-independent adenosine release under control conditions (Wall and Dale, 2007). The effects of bafilomycin strongly support our hypothesis that adenosine is released by exocytosis from parallel fibers.

\section{Discussion}

The metabolism of ATP to adenosine is greatly reduced $(>90 \%)$ in the cerebellum from mice deficient in the enzyme CD73 $\left(C D 73^{-1-}\right)$, a phenotype that can be rescued by the addition of $5^{\prime}$-nucleotidase. Using these mice, we have identified the role of extracellular ATP metabolism in spike-evoked adenosine release. Adenosine release consists of two separate components, glutamate receptor dependent and independent (Klyuch et al., 2012), which are of approximately equal amplitude in $C D 73^{+/+}$mice. However, the component of adenosine release that depends on ionotropic glutamate receptor activation is absent in $C D 73^{-1-}$ mice and therefore depends on the prior release of ATP. The cellular basis of this pathway is unclear, but the release of glutamate from parallel fibers could activate receptors on astrocytes, which then release ATP that is subsequently converted to adenosine (Queiroz et al., 1997; Loiola and Ventura, 2011). The second component of adenosine release had no dependence on ionotropic glutamate receptor activation and was unaffected by the deletion of CD73. This second component therefore represents the direct spike-dependent release of adenosine. This result overturns the current consensus that adenosine is not directly released except under pathological conditions (Pascual et al., 2005; Halassa and Haydon, 2010). The dynamics of the indirect and direct pathways of adenosine release are so similar that our biosensor measurements could not distinguish them, thus the breakdown of ATP that underlies the indirect pathway must be rapid. However, the rise and decay of the biosensor current is dominated by the rate of diffusion of purines from the slice surface and the prolonged release process (train of stimuli) reduces temporal resolution (Klyuch et al., 2011).

This direct release of adenosine has several hallmarks of exocytosis: $\mathrm{Ca}^{2+}$ and action potential dependence, short-term plasticity, and modulation by G-protein-coupled receptors (Wall and Dale, 2007; Klyuch et al., 2011, 2012). The effects of bafilomycin, which prevents vesicular refilling, abolishes adenosine release and strongly supports exocytotic release and the existence of a proton-dependent adenosine vesicular transporter. The effects of bafilomycin rule out alternative mechanisms of adenosine release, which have similar characteristics. For example, volumeactivated anion channels release ATP in response to action potentials and have a gating requirement for $\mathrm{Ca}^{2+}$ (Fields and $\mathrm{Ni}$, 2010). However this mechanism is not blocked by bafilomycin, and any channel-mediated mechanism of adenosine release would require high intracellular concentrations of adenosine (millimolar concentration range) to provide a sufficient chemical gradient. The intracellular concentration of adenosine is generally limited by adenosine kinase and $S$-adenosylhomocysteine hydrolase (Boison, 2006). A high intracellular concentration of adenosine would also result in significant continual efflux of adenosine via the ENTs, something that is not observed in cerebellar slices (Wall et al., 2007).

The modulation of direct adenosine release, by activation of mGlu4 receptors, supports the hypothesis (Wall and Dale, 2007) that adenosine originates from parallel fibers. This direct action 
potential-evoked release of adenosine is likely to mediate physiologically significant inhibition, including feedback inhibition via adenosine $A_{1}$ receptors present on the presynaptic terminals of parallel fibers (Wall and Dale, 2007). The exocytosis of adenosine provides a rapid and dynamic mechanism of adenosine release, which would directly correlate with the degree of neural activity and thus could contribute to physiological processes such as sleep, where extracellular adenosine accumulates (Palchykova et al., 2010). Like other neurotransmitters, the exocytosis of adenosine would require some form of vesicular transporter to fill the vesicles with adenosine. Recent evidence suggests that adenosine concentrative transporters are present on synaptic vesicles in the striatum (Melani et al., 2012) but because they are $\mathrm{Na}^{+}$dependent they may not play a role in vesicular filling. The identification of a vesicular adenosine transporter and its mechanism of action will be a priority of future work.

\section{References}

Abbracchio MP, Burnstock G, Verkhratsky A, Zimmermann H (2009) Purinergic signalling in the nervous system: an overview. Trends Neurosci $32: 19-29$.

Boison D (2006) Adenosine kinase, epilepsy and stroke: mechanisms and therapies. Trends Pharmacol Sci 27:652-658.

Dale N, Frenguelli BG (2009) Release of adenosine and ATP during ischemia and epilepsy. Curr Neuropharmacol 7:160-179.

Fields RD, Ni Y (2010) Nonsynaptic communication through ATP release from volume-activated anion channels in axons. Sci Signal 3:ra73.

Gereau RW 4th, Conn PJ (1994) Potentiation of cAMP responses by metabotropic glutamate receptors depresses excitatory synaptic transmission by a kinase-independent mechanism. Neuron 12:1121-1129.

Halassa MM, Haydon PG (2010) Integrated brain circuits: astrocytic networks modulate neuronal activity and behavior. Annu Rev Physiol 72:335-355.

Klyuch BP, Richardson MJ, Dale N, Wall MJ (2011) The dynamics of single spike evoked adenosine release in the cerebellum. J Physiol 589:283-295.

Klyuch BP, Dale N, Wall MJ. (2012) Receptor-mediated modulation of activity-dependent adenosine release in rat cerebellum. Neuropharmacology 62:815-824.

Koszalka P, Ozüyaman B, Huo Y, Zernecke A, Flögel U, Braun N, Buchheiser A, Decking UK, Smith ML, Sévigny J, Gear A, Weber AA, Molojavyi A,
Ding Z, Weber C, Ley K, Zimmermann H, Gödecke A, Schrader J (2004) Targeted disruption of cd73/ecto-5' -nucleotidase alters thromboregulation and augments vascular inflammatory response. Circ Res 95:814-821.

Langer D, Hammer K, Koszalka P, Schrader J, Robson S, Zimmermann H (2008) Distribution of ectonucleotidases in the rodent brain revisited. Cell Tissue Res 334:199-217.

Llaudet E, Botting NP, Crayston JA, Dale N (2003) A three-enzyme microelectrode sensor for detecting purine release from the central nervous system. Biosens Bioelectron 18:43-52.

Loiola EC, Ventura AL (2011) Release of ATP from avian Müller glia cells in culture. Neurochem Int 58:414-422.

Mateos JM, Azkue J, Sarría R, Kuhn R, Grandes P, Knöpfel T (1998) Localization of the mGlu4a metabotropic glutamate receptor in rat cerebellar cortex. Histochem Cell Biol 109:135-139.

Melani A, Corti F, Stephan H, Müller CE, Donati C, Bruni P, Vannucchi MG, Pedata F (2012) Ecto-Atpase inhibition: ATP and adenosine release under physiological and ischemic in vivo conditions in the rat striatum. Exp Neurol 233:193-204.

Palchykova S, Winsky-Sommerer R, Shen HY, Boison D, Gerling A, Tobler I (2010) Manipulation of adenosine kinase affects sleep regulation in mice. J Neurosci 30:13157-13165.

Pascual O, Casper KB, Kubera C, Zhang J, Revilla-Sanchez R, Sul JY, Takano H, Moss SJ, McCarthy K, Haydon PG (2005) Astrocytic purinergic signalling coordinates synaptic networks. Science 310:113-116.

Queiroz G, Gebicke-Haerter PJ, Schobert A, Starke K, von Kügelgen I (1997) Release of ATP from cultured rat astrocytes elicited by glutamate receptor activation. Neuroscience 78:1203-1208.

Wall MJ, Dale N (2007) Auto-inhibition of rat parallel fibre-Purkinje cell synapses by activity-dependent adenosine release. J Physiol 581:553-565.

Wall MJ, Atterbury A, Dale N (2007) Control of basal extracellular adenosine concentration in rat cerebellum. J Physiol 582:137-151.

Wall MJ, Wigmore G, Lopatár J, Frenguelli BG, Dale N (2008) The novel NTPDase inhibitor sodium polyoxotungstate (POM-1) inhibits ATP breakdown but also blocks central synaptic transmission, an action independent of NTPDase inhibition. Neuropharmacology 55:1251-1258.

Zhou Q, Petersen CC, Nicoll RA (2000) Effects of reduced vesicular filling on synaptic transmission in rat hippocampal neurones. J Physiol 525:195-206.

Zimmermann H (2000) Extracellular metabolism of ATP and other nucleotides. Naunyn-Schmiedebergs Arch Pharmacol 362:299-309. 